\title{
Beide Beine abdecken
}

\author{
Dankward Höntzsch
}

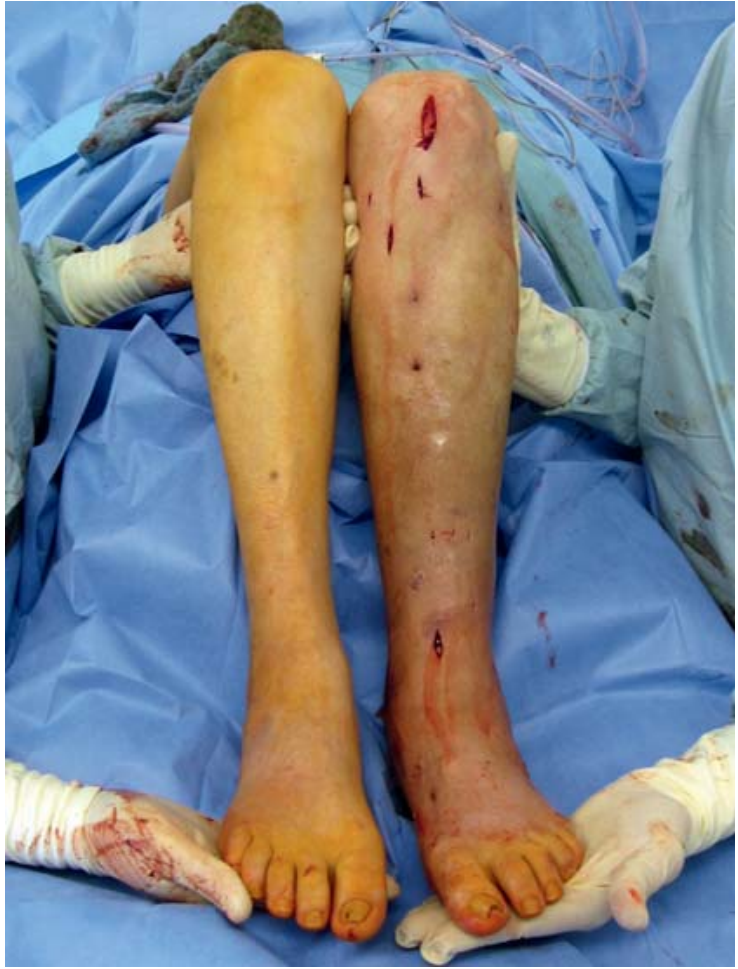

Bei Operationen, bei denen es schwierig ist, die Achsen und die Rotation genau einzuhalten und bei denen es auf eine genaue laterale Durchleuchtung insbesondere am Femur ankommt, bewährt sich das beidseitige Abdecken der unteren Extremität.

Das gesunde Bein ist dann die Vorlage. So lassen sich die Achsen für den Varus und Valgus sowie die Rotation sehr genau bestimmen ( $\bullet \mathbf{A b b} \mathbf{~} \mathbf{1}$ bis $\mathbf{3}$ ).

Wenn man einen Vergleich hat, ist das Auge hierfür sehr empfindlich. Man denke nur an ein Bild, das schief hängt. Man sieht ein schräg hängendes Bild schon ab 1 bis $2^{\circ}$ Neigung.

Dieses beidseitige Abdecken ist für das Femur und die Tibia sehr hilfreich.

Für den Femurschaft und das proximale Femur wird der lateromediale oder mediolaterale Strahlengang der Bildwandlerkontrolle wesentlich erleichtert; diese erfolgt dann mit weniger Aufwand und mit exakterem Ergebnis ( Abb. 4).

- Abb. 1 Besonders bei schwierigen, aber bitte auch bei einfachen Verhältnissen erleichtert das beidseitige Abdecken die Kontrolle von Rotation, Achsen und Länge wesentlich, hier am Beispiel einer Nagelung der Tibia.
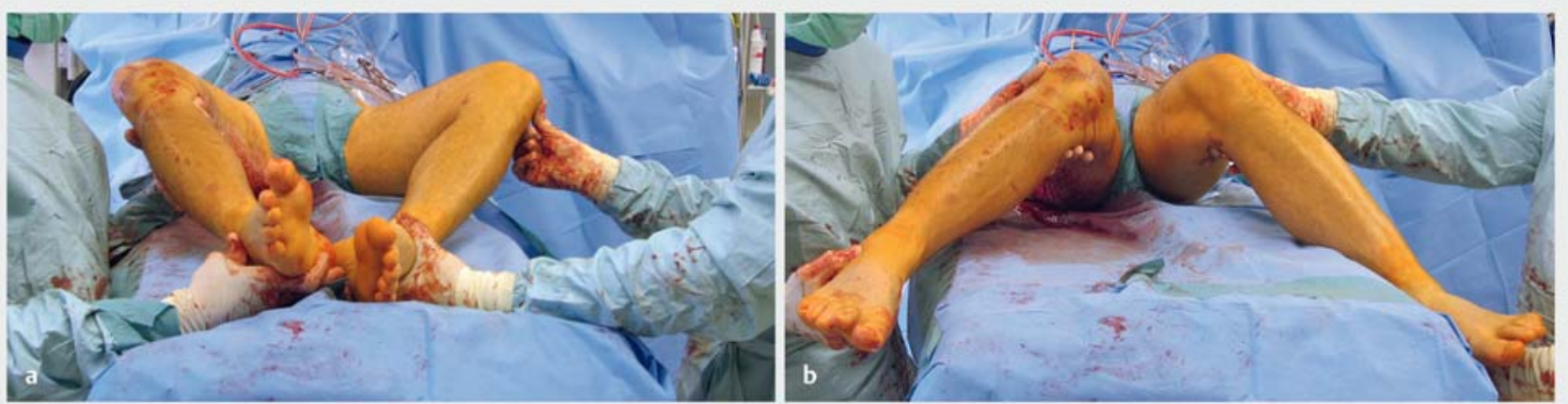

> Abb. 2 Unzählige Tipps wurden zum Thema Einstellung der „Rotation bei der Behandlung von Femurfrakturen“ bereits vorgestellt. Trotzdem beschreibt die Literatur weiterhin eine signifikante Rate von Rotationsabweichungen, besonders am Femur. Mit beidseitigem Abdecken gibt es eine einfache und sichere Alternative, zudem ganz ohne zusätzliche Röntgentricks. 


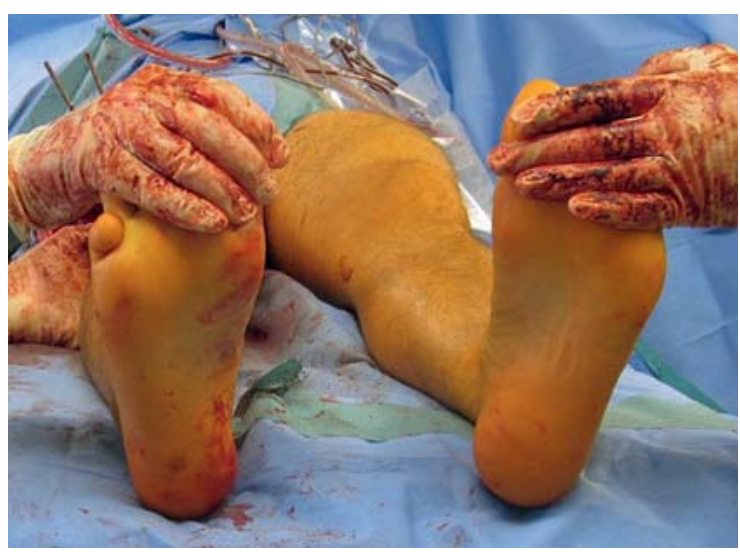

- Abb. 3 Auch die Länge lässt sich sehr einfach durch Vergleich mit dem anderen Bein kontrollieren.

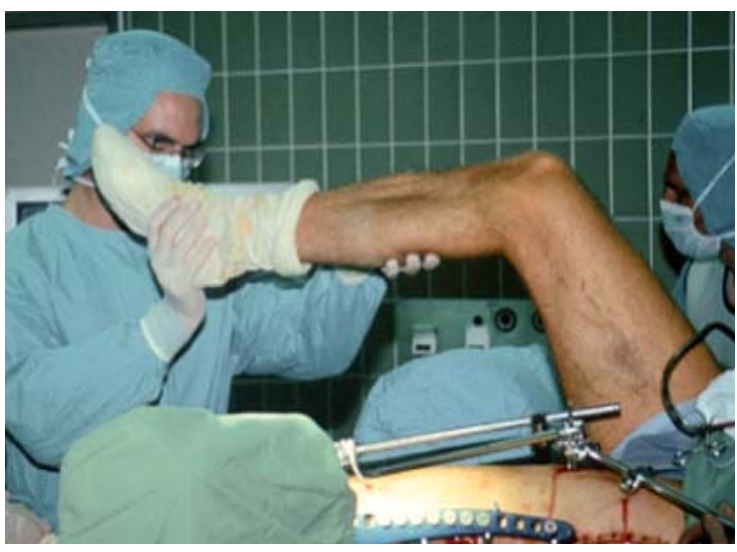

- Abb. 4 Besonders am Femur (proximal, Schaft und distal!) ist die exakte seitliche BV-Einstellung schwierig und manchmal nur "halblebig“, dabei ist sie so wichtig. Auch hier hilft die beidseitige Abdeckung, weil man das Gegenbein einfach aus dem Strahlengang herausheben kann.

Bibliografie

DOI https://doi.org/10.1055/a-0647-2510

Online-publiziert 05.10.2018 | OP-JOURNAL 2018; 34: 331332 @ Georg Thieme Verlag KG Stuttgart · New York ISSN 0178-1715 